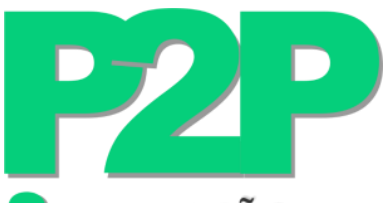

INOVAÇÃO

\title{
EXPEDIENTE / EDITORIAL TEAM
}

\section{EDITOR GERAL/ EDITOR}

Clovis R. Montenegro de Lima

http://lattes.cnpq.br/4727891485011869

\section{EDITORES ADJUNTOS/ EDITORIAL ASSISTANTS}

Eula Dantas Taveira Cabral

http://lattes.cnpq.br/1180749525319069

Rose Marie Santini

http://lattes.cnpq.br/8757803805826489

Tirza Cardoso Ferreira Rodrigues Vargas

http://lattes.cnpq.br/0786948390376844

\section{COLABORADORES/ CONTRIBUTORS}

Cintia Belém

http://lattes.cnpq.br/4572163874253924

\section{CAPA/ COVER}

Giovana Aparecida Zimermann

http://lattes.cnpq.br/8461759740569690

\section{TRADUÇÕES/ TRANSLATIONS}

Clovis R. Montenegro de Lima

clovisml@gmail.com

Elisa Perfeito

elisatraducao@gmail.com 